\title{
Erratum to: Characterization of submarine canyon bathymetries in northern Ionian Sea, Italy, using sediment geochemical variation induced by transportation distance and basin depth
}

Francesco Perri $^{1} \cdot$ Tohru Ohta $^{2} \cdot$ Salvatore Critelli $^{1}$

Published online: 5 August 2015

(C) Springer-Verlag Berlin Heidelberg 2015

Erratum to: Int J Earth Sci (Geol Rundsch) (2015)

104:1353-1364

DOI 10.1007/s00531-015-1150-x

Inadvertently, the authors' first and family names were interchanged in the original published article. The correct author group is given below.

Francesco Perri

Tohru Ohta

Salvatore Critelli

The online version of the original article can be found under doi:10.1007/s00531-015-1150-x.

Francesco Perri

francesco.perri@unical.it

Tohru Ohta

tohta@waseda.jp

Salvatore Critelli

salvatore.critelli@unical.it

1 Dipartimento di Biologia, Ecologia e Scienze della Terra, Università degli Studi della Calabria, Via P. Bucci, 87036 Arcavacata di Rende, CS, Italy

2 Department of Earth Sciences, Faculty of Education and Integrated Arts and Sciences, Waseda University, 1-6-1, Nishiwaseda, Shinjuku-ku, Tokyo 169-8050, Japan 